\title{
0177 RESULTS OF OPERATIVE STABILISATION OF LONG BONE FRACTURES AT A TROPICAL TERTIARY HEALTH INSTITUTION: A 14-YEAR REVIEW
}

A 0 Ifesanya, ${ }^{*}$ S 0 Ogunlade, A B Omololu, T 0 Alonge Correspondence: Division of Orthopaedics and Trauma, Department of Surgery, College of Medicine, University College Hospital, Ibadan, PMB 5116, Queen Elizabeth Road, badan 23402, Nigeria

\subsection{6/ip.2010.029215.177}

Orthopaedic implant surgery is often regarded as risky in developing countries due to likely hardware infection and the perception that the technical know-how are unavailable. The outcome of operative fixation of fractures at our centre was evaluated to determine whether this should be an option in our environment or not. All open reduction and internal fixation of fractures done at our hospital between September 1995 and December 2008 were reviewed. Details of the fractures, indications for surgery, fixation technique and outcome measures were recorded. A total of 524 fractures in 456 patients out of 1003 long bone fractures operatively stabilised during the period. About $15 \%$ were open fractures while a quarter of fractures involved the femoral shaft. Mean age of patients was 34.0 years. Traffic injuries accounted for $64 \%$ of cases. Average follow up period was 11.1 months. Plate osteosynthesis was employed in 330 cases $(63.0 \%)$. Associated injuries and infective wound complications prolonged hospital stay. Complication rate was $21.0 \%$, joint stiffness in $7.8 \%$ and chronic osteomyelitis in $3.8 \%$. Open fractures and multiple long bone fracture stabilisation were associated with increased risks of chronic osteomyelitis. Although plate osteosynthesis remains the mainstay of long bone fracture stabilisation at our centre due to the lack of instrumentation for closed nailing, our results are comparable to those from other parts of the world. Open reduction and internal fixation is a recommendable option in treatment of fractures and nonunions in the 3rd world if standard precautions are observed. 